\title{
A EFICÁCIA DO DIREITO FUNDAMENTAL DE ACESSO À JUSTIÇA PELA EFETIVIDADE DO DIREITO DE RAZOÁVEL DURAÇÃO DO PROCESSO
}

\author{
A FUNDAMENTAL RIGHT TO EFFECTIVE ACCESS TO JUSTICE \\ FOR THE EFFECTIVENESS OF REASONABLE PROCESS \\ DURATION OF LAW \\ Ana Paula Goldani Martinotto Reschke ${ }^{1}$ \\ Narciso Leandro Xavier Baez ${ }^{1}$
}

Recebido em: 04/05/2017 Aceito em: 06/07/2017

apgoldani@yahoo.com.br narciso.baez@gmail.com
Resumo: O acesso à justiça é direito humano fundamental e deve ser protegido e promovido pelo Estado de forma substancial, como a possibilidade de se buscar uma decisão justa e que resolva o litígio em tempo razoável, por estar vinculado à dignidade da pessoa humana. Cabe ao Estado a implementação de condutas negativas e positiva para a concretização dos direitos fundamentais, posto que amplamente relacionado com a dignidade da pessoa humana, as quais também devem ser exercidas pelos cidadãos em suas relações particulares. Portanto, na presente pesquisa, deve ser verificada qual a eficácia do direito de acesso à justiça em relação ao direito fundamental de razoável duração do processo sob o ponto de vista da teoria da eficácia dos direitos fundamentais. Assim, busca-se averiguar a teoria da eficácia dos direitos fundamentais, na sua vertente imediata e mediata e, ainda, analisar o direito de acesso à justiça a partir da concepção da razoável duração do processo, direito este fundamental estabelecido com a Emenda Constitucional 45 de 2004. Por fim, identificar a efetiva aplicação da teoria da eficácia dos direitos fundamentais em relação ao acesso à justiça pela verificação ou violação da razoável duração do processo. Assim, por meio de pesquisas em bibliografias e em artigos jurídicos, este artigo pretende colaborar na busca de razões adequadas sobre o acesso à justiça relacionados com a teoria da eficácia dos direitos fundamentais a partir de uma análise do direito à duração razoável do processo.

Palavras-chave: Eficácia dos direitos fundamentais. Acesso à Justiça. Duração razoável do processo.

\begin{abstract}
Access to justice is a fundamental human right and must be protected and promoted by the State substantially as the possibility of seeking a just decision and to resolve the dispute within a reasonable time, to be linked to human dignity. The State implementation of negative and positive behaviors to the realization of fundamental rights, since it largely related to the dignity of the human person, which must also be exercised by citizens in their private relationships. Therefore, in this research, which must be verified the effectiveness of the right of access to justice in relation to the fundamental right to reasonable length of proceedings from the point of view of the effectiveness of the theory of fundamental rights. Thus, they seek to ascertain the theory of the effectiveness of fundamental rights, in the immediate and mediate strand and also analyze the right of access to justice from the reasonable duration of the process design, a right fundamental established by Constitutional Amendment 452004 Finally, identify the effective application of the theory of the effectiveness of fundamental rights in relation to access to justice by check or violation of reasonable duration of the process. Thus, through research in bibliographies and legal articles, this article intends to collaborate in the search for appropriate reasons on access to justice related to the theory of the effectiveness of fundamental rights from an analysis of the right to reasonable length of proceedings.
\end{abstract}

Keywords: Access to Justice. Fundamental rights. Reasonable duration of the process.

\footnotetext{
${ }^{1}$ Universidade do Oeste de Santa Catarina - UNOESC - Joaçaba - Santa Catarina - Brasil
} 


\section{INTRODUÇÃO}

Muito se fala em acesso à justiça, inclusive sendo este reconhecido como direito humano. Contudo, um dos aspectos que torna efetivo esse direito, não só no seu aspecto formal, mas também e principalmente no seu aspecto substancial, é a sua tramitação em tempo razoável, que venha a proporcionar uma prestação jurisdicional justa e adequada ao caso em concreto. Mas será que a razoável duração do processo pode ser fator de eficácia do direito de acesso à justiça?

A partir disso, a presente pesquisa busca resolver a questão problema sobre a efetiva aplicação da teoria da eficácia dos direitos fundamentais para a efetivação do direito fundamental de acesso à justiça a partir da concepção de razoável duração do processo, ou seja, se podemos visualizar a eficácia desse direito humano fundamental ou sua violação.

Para tanto, se faz necessário estabelecer uma breve análise da teoria da eficácia dos direitos fundamentais nas suas diversas concepções, bem como identificar a razoável duração do processo como elemento de acesso à justiça e, por fim, verificar a aplicabilidade da teoria da eficácia dos direitos fundamentais para efetivação do direito de acesso à justiça a partir da concepção de razoável duração do processo.

O presente trabalho se faz importante na medida em que se presencia dois fatores preocupantes em relação ao processo em geral, sendo a morosidade que hoje afeta sobre maneira a prestação jurisdicional, bem como a celeridade processual que vem sendo implantada com as reformas no sistema processual, desde a edição da Emenda Constitucional 45/2004, fatores estes que podem se configurar mais em violadores do direito fundamental de razoável duração do processo e que se tornam obstáculos do direito de acesso à justiça. Aonde a teoria da eficácia dos direitos fundamentais se torna aplicável nessa situação?

Para tanto, por meio de pesquisas bibliográficas e também em artigos jurídicos, o presente artigo pretende buscar colaborar na busca da teoria da eficácia dos direitos fundamentais a ser aplicada no caso em concreto ou, até mesmo, buscando evidenciar e constatar a sua real aplicação ou não de tal teoria.

\section{TEORIA DA EFICÁCIA DOS DIREITOS FUNDAMENTAIS}

Os direitos fundamentais representam importante transformação do direito na medida em que se reconhecem perante as Constituições valores intrínsecos aos seres humanos e que devem ser observados pelo Estado na sua relação jurídica com o indivíduo, bem como entre os próprios cidadãos em suas relações particulares ${ }^{2}$.

\footnotetext{
${ }^{2} \mathrm{O}$ fim da Segunda Guerra Mundial apresentou à humanidade um prato de difícil digestão: a banalidade do mal, produzindo efeitos variados nas diferentes áreas do conhecimento humano. No direito em geral e, no constitucional em particular, esses eventos representaram o ápice do processo de superação do positivismo jurídico, que havia se tornado dominante nas primeiras décadas do século, e um retorno à ideia [sic] de valores. Voltou-se a reconhecer, humildemente, que o direito não surge no mundo por si só, mas relaciona-se de forma indissociável com valores que lhe são prévios, ideais de justiça e de humanidade que humana e na experiência civilizatória dos povos. (BARCELLOS, 2002, p. 23-24).
} 
É sobretudo a partir do século XX que estes valores se intensificam e declarações são editadas levando ao neoconstitucionalismo, tendo em vista os direitos humanos se "proliferaram gerando o reconhecimento de novos direitos" ${ }^{3}$ bem como sua característica de direitos fundamentais, sendo positivados nas constituições na era do Estado moderno sendo esta característica que diferencia os direitos humanos dos direitos fundamentais.

O termo < direitos fundamentais $>$, droits Fundamentaux aparece na França em 1770 num movimento poítico e cultural que levou à Declaração dos Direitos do Homem e do Cidadão de 1789. A epressão logo alcançou a Alemanha, onde, sob o título de Grundrechte articulou o sistema de relações entre o indivíduo e o Estado, como fundamento de toda a ordem jurídica e política . Este é o seu sentido em 1949 Bonn Grundgesetz . Por isso grande parte da doutrina entende que os direitos humanos fundamentais são aqueles direitos positivado em constituicões estado.(PÉRES LUÑO, 1991, p. 11, tradução nossa). ${ }^{4}$

São "direitos fundamentais os direitos positivados em determinada ordem constitucional positiva, enquanto os direitos humanos dizem respeito àqueles consagrados em documentos internacionais, desvinculados internamente e sem limitação temporal". (CANOTILHO, 2002, p. 393).

Até o século XIX, o Estado Liberal de Direito entendia a relação de direitos fundamentais apenas a partir do liame jurídico entre Estado e Cidadão, sendo reconhecido ao indivíduo que os direitos fundamentais possuíam caráter de direito subjetivo, sendo marcante a distância entre direito público e direito privado. É com a busca pelo estado social que se verifica maior proximidade do direito privado ao direito constitucional e, desta forma, reconhecimento da observância dos direitos fundamentais também entre os particulares. ${ }^{5}$

A teoria dos direitos fundamentais entre particulares ou Drittwirkung, como é conhecida na Alemanha, surgiu em meados dos anos 50, com a intenção de sua promoção nas relações que envolvam os direitos fundamentais nas relações privadas. (FABIAN 2002, p. 71).

\footnotetext{
${ }^{3}$ Essa multiplicação (ia dizendo "proliferação') ocorreu de três modos: a) porque aumentou a quantidade de bens considerados merecedores de tutela; b) porque foi estendida a titularidade de alguns direitos típicos a sujeitos diversos do homem; c) porque o próprio homem não é mais considerado como ente genérico, ou homem em abstrato, mas é visto na especificidade ou na concreticidade de suas diversas maneiras de ser em sociedade, como criança, velho, doente, etc. em substância: mais bens, mais sujeitos mais status do indivíduo. (BOBBIO, 2004, p. 63).

${ }^{4}$ El término <derechos fundamentales>, droits fondamentaux aparece em Francia hacia 1770 em el movimento poítico y cultural que condujo a la Declaración de los Derechos del Hombre y del Ciudadano de 1789. La expresión há alcanzado luego especial relieve em Alemania, donde bajo el título de los Grundrechte se há articulado el sistema de relaciones entre el individuo y el Estado, em cuanto fundamrnto de todo el orden jurídico-político. Este es su sentido em la Grundgesetz de bonn de 1949.

De ahí que gran parte de la doctrina entienda que los derechos fundamentales son aquellos derechos humanos positivizados em las constitucioones estatales. (PÉRES LUÑO, 1991, p. 11).

${ }^{5}$ De acordo com Nipperdey, "os direitos fundamentais (...) têm de existir em uma sociedade bem justa, liberal e socialmente ordenada, que seu efeito não pode ser limitado à relação de estado e cidadão, mas também tem de valer para os consortes jurídicos uns com os outros. (NIPPERDEY, 2012, p.62).
} 
A partir desse fundamento, é possível reconhecer que os direitos fundamentais possuem uma dupla dimensão, pois que emanam posições subjetivas dos cidadãos em face do Estado bem como veiculam determinada ordem objetiva de valores tendentes a comandar a vida em sociedade, ou seja, a relação entre particulares. Desta forma, podem ter o que se denomina de "eficácia privada ou externa" e ainda "eficácia horizontal", ou seja, em relação a terceiro ou Drittwirkung..

No ordenamento jurídico brasileiro, a eficácia dos direitos fundamentais decorre da vinculação exarada pelo princípio da máxima eficácia e efetividade que os mesmos possuem (artigo $5^{\circ}, \S 1^{\circ}$, da Constituição Federal). Referido princípio vincula o poder público, o legislador privado e os órgãos jurisdicionais a utilizar os direitos fundamentais na solução dos litígios entre os particulares (SARLET, 2009, p. 140). Assim, embora não haja, como existe em outros ordenamentos jurídicos, cláusula constitucional expressa sobre a aplicação dos direitos fundamentais às relações privadas, o citado parágrafo funciona como base constitucional para essa aplicação.

Estabelecido o permissivo constitucional para a aplicação, cumpre sejam tecidas algumas considerações sobre os seus fundamentos. A doutrina elenca dois argumentos para a vinculação dos particulares aos direitos fundamentais.

O primeiro se relaciona com a própria evolução do Estado. Sabe-se que inicialmente os direitos fundamentais eram concebidos como direitos essencialmente de defesa do cidadão perante o Estado (primeira dimensão dos direitos fundamentais), entretanto, com o advento do Estado Social de Direito ampliam-se as funções do Estado, de modo que este, mais do que não atentar contra os direitos fundamentais de seus cidadãos, deve também (dentre outros deveres) protegê-los de agressões a seus direitos fundamentais. (SARLET, 2009, p. 118)

Disso decorre reconhecer que não raro os cidadãos têm seus direitos fundamentais lesados pela ação de outro cidadão, cabendo ao Estado também proteger os direitos fundamentais do particular lesado. Podemos citar aqui como exemplo o julgado do STF RE 160.222-8, que julgou ilegal a revista íntima de empregadas de uma determinada fábrica de lingerie, que utilizava de tal prática para evitar possíveis furtos por parte das empregadas. $\mathrm{O}$ argumento foi de que a "dignidade humana" ${ }^{16}$ destas mulheres estava sendo lesada, causando assim constrangimento ilegal.

Por outro lado, "a dimensão jurídico-objetiva dos direitos fundamentais - os direitos fundamentais exprimem valores que o Estado não deve somente respeitar, mas também promover e proteger - impõe a irradiação dos valores por todo o ordenamento jurídico, o que abrange, por consequência, as relações jurídicas entre privados". (SARLET, 2009, p.118). Ou seja, essa perspectiva estabelece a eficácia irradiante dos direitos fundamentais, pois estes "fornecem impulsos e diretrizes para a aplicação e interpretação do direito infraconstitucional, o que, além disso, apontaria para a necessidade de uma interpretação conforme aos direitos fundamentais, (...)"(SARLET, 2009, p. 147).

\footnotetext{
${ }^{6} \mathrm{O}$ fundamento do ordenamento jurídico total, portanto, também do direito privado, é a dignidade da pessoa. (...) a dignidade humana é, então, realizada, quando ela assegura uma esfera, na qual ela pode atuar como ser independente e moralmente autorresponsável, na qual ela nem é submetida a pretensão de poder de uma outra pessoa, nem é transformada em mero meio de uma finalidade comunitária, mas é pessoa autorresponsável livre.(NIPPERDEY, 2013, p.52).
} 
Nesse sentido, mostra-se interessante a exposição de Vieira de Andrade, que destaca duas direções a partir as quais o problema pode ser analisado:

(...) em primeiro lugar, afirma-se que os direitos fundamentais como princípios e valores constitucionais não podem deixar de aplicar-se em toda a ordem jurídica e, portanto, também nas esferas do direito privado e penal (princípio da unidade do ordenamento jurídico); em segundo lugar, põe-se em relevo a necessidade de proteção dos particulares não apenas perante o Estado, mas também, através do Estado, perante outros particulares, pelo menos, perante indivíduos ou entidades privadas que sobre eles exercem ou estão em condições de exercer verdadeiros poderes, jurídicos ou de facto. (DE ANDRADE, 2003, 274).

Diante do exposto, a doutrina de forma geral concorda com a aplicação dos direitos fundamentais às relações privadas. Embora a doutrina concorde com essa aplicação, há grandes divergências sobre o modo como isso ocorrerá 7 .

Os divergentes dividem-se em duas correntes, aqueles que defendem uma aplicação direta dos direitos fundamentais às relações particulares e aqueles que defendem que essa aplicação deve ocorrer de modo indireto. TEORIA MEDIATA E IMEDIATA

Os partidários da primeira corrente aduzem que se os direitos fundamentais estabelecem valores aplicáveis a toda a ordem jurídica e estão previstos na Constituição, cuja força normativa é a superior dentro de um ordenamento jurídico, não haveria possibilidade de entender que o direito privado se encontra alheio a essas características. Assim, a aplicação dos direitos fundamentais às relações privadas se daria de modo direto, sem que houvesse a necessidade de qualquer atuação legislativa ou jurisdicional intermediária. (SARLET, 2009, 379).

Já aqueles que adotam uma aplicação indireta entendem que os direitos fundamentais seriam aplicados às relações privadas por meio de uma intermediação feita pelo legislador ou pelos magistrados "por meio de uma interpretação conforme aos direitos fundamentais e, eventualmente, por meio de uma integração jurisprudencial de eventuais lacunas, cuidando-se, na verdade, de uma espécie de recepção dos direitos fundamentais pelo Direito Privado". (SARLET, 2009, 123-124) Ou seja,

Cabe ao legislador privado resolver as colisões que inevitavelmente se estabelecem no âmbito das relações entre particulares, todos titulares de direitos fundamentais, devendo o Juiz realizar esta tarefa apenas na ausência de norma legal incidente ou, na melhor das hipóteses, para atuar de forma corretiva, no caso de a lei ser manifestamente inconstitucional, especialmente por ofensiva aos direitos fundamentais. Na ausência do

\footnotetext{
${ }^{7}$ Ressalta-se que essa divergência não abrange aqueles direitos fundamentais essencialmente destinados aos particulares, bem como aqueles cuja observância cabe somente ao poder público.
} 
legislador, o Juiz deveria limitar-se a interpretar o direito infraconstitucional à luz das normas de direitos fundamentais, notadamente fazendo uso dos conceitos indeterminados e das cláusulas gerais do Direito Privado (...). (SARLET, 2009, 142).

Ainda, alguns doutrinadores admitem a aplicação direta dos direitos fundamentais no caso dos chamados "poderes privados". Assim, quando, em uma relação entre particulares, se verificasse que um deles possui expressivo poder social, estar-se-ia diante de uma relação semelhante àquele entre cidadão e Estado, justificando-se a aplicação direta dos direitos fundamentais, como uma eficácia vertical e não horizontal (SARLET, 2009, 128). Trata-se de teoria muito criticada, pois iguala situações em muitos diferentes, na medida em que por mais forte que seja um dos particulares, jamais poderá ser igualado ao Estado.

Assim, pode-se concluir que:

o critério da "desigualdade" ou do "poder social" não deve, por isso, ser entendido como um critério classificatório, que nos permitisse em abstrato determinar as entidades que, além do Estado e das demais pessoas colectivas públicas, seriam sujeitos passivos dos direitos fundamentais. Ele é, sobretudo, um critério teleológico que em concreto permite estender por analogia e graduar a eficácia dos direitos e liberdades nas relações privadas. (DE ANDRADE, 2003, p. 286).

Cumpre referir a existência da chamada doutrina do state action, adotada principalmente nos Estados Unidos, que considera que os direitos fundamentais previstos na Constituição apenas vinculam o Estado, sendo invocáveis somente quando se está diante de uma ação estatal. As condutas primordialmente privadas estariam fora do âmbito de proteção dos direitos fundamentais. Entretanto, essa teoria vem sendo relativizada em algumas situações, quais sejam: a) quando o particular exerce uma atividade estatal típica; b) quando existam elementos suficientes para se permitir impor ao Estado a responsabilidade pela conduta praticada pelo particular. (SARLET, 2009, 134).

Assim, verifica-se que quanto à possibilidade da aplicação dos direitos fundamentais às relações particulares não existem grandes divergências doutrinárias, mas quando se trata de estabelecer em que medida ocorrerá essa aplicação existem posicionamentos diversos.

Para Wilson Antônio Steinmetz, a vinculação dos particulares a direitos fundamentais é um problema de eficácia de normas de direitos fundamentais nas relações jurídicas entre particulares. Eficácia é o predicado da norma que se refere à capacidade técnica de produzir efeitos jurídicos (STEINMETZ, 2004, p. 40).

Portanto, a questão primordial é estabelecer que os direitos fundamentais se compõe de direitos subjetivos do cidadão em face do Estado, este entendimento é pacificado. Contudo, quando se trata de relação entre particulares é que vem o dilema, ou seja, até onde pode o Estado interferir 
para fazer cumprir direitos fundamentais nas relações privadas. Além disso, é de verificar-se, ainda, e este é o propósito deste trabalho, qual a eficácia do direito humano fundamental de acesso à justiça, isso a partir do direito fundamental de razoável duração do processo.

Resta a verificação se há efetivamente a aplicação desta teoria nesta situação ou se presenciamos uma violação desse direito fundamental (de acesso à Justiça) por não observância, tanto pelo Estado como pelos particulares, na relação processual, do razoável tempo que o processo necessita para garantir uma justa e plena entrega da prestação jurisdicional que, inevitavelmente, reflete no acesso substancial à justiça.

\section{A RAZOÁVEL DURAÇÃO DO PROCESSO COMO ELEMENTO DE ACESSO À JUSTIÇA}

Quando se fala em acesso à justiça duas questões devem ficar muito claras, ou seja, que se está a tratar de um direito humano bem como da dignidade da pessoa humana. Portanto, se exige especial atenção para sua proteção e promoção tanto pelo Estado como pela sociedade, seja através de condutas negativas, visando não cerceá-la nem degradá-la ou ainda por meio de condutas positivas, na busca de meios de sua promoção em prol do ser humano ${ }^{8}$.

Tal fato demonstra que deve-se desenvolver meios que assegurem condições dignas de vida aos cidadãos através do que é chamado de mínimo existencial, o que está implicitamente relacionado com a dignidade da pessoa humana e que fundamenta as condutas a serem adotadas tanto pela sociedade como pelo Estado em relação à dignidade do homem. ${ }^{9}$

A evolução desse conceito tem se envolvido com a concepção de que a pobreza e marginalidade são assuntos do interesse do Estado por tratarem de direitos básicos de que necessita uma pessoa para sua sobrevivência no meio social e, portanto, esse mínimo existencial deve ser promovido através de condutas positivas mediante ações sociais que inclui "a assistência social aos cidadãos, que, em virtude de sua precária condição física e mental, encontram-se limitados na sua vida social não apresentando condições de prover sua própria subsistência. ${ }^{10}$

Não há como se estabelecer um rol taxativo do que e quais são os elementos que compõe um mínimo existencial, tendo em vista que necessidades vão surgindo diante das relações sociais cada vez mais complexas, o que exige a necessidade de reconhecimento de direitos básicos tidos como um mínimo existencial para os cidadãos. ${ }^{11}$

\footnotetext{
${ }^{8}$ A dignidade da pessoa humana deve ser assim respeitada tanto como princípio moral essencial como enquanto disposição de direito positivo. Respeitar a dignidade do homem exige obrigações positivas". (SARLET, 2005, p. 86).

${ }^{9}$ A dignidade da pessoa humana e o assim chamado mínimo existencial são atualmente noções tidas como indissociáveis, cuidando-se, ademais, de figuras praticamente onipresentes no atual debate (pelo menos é o que se observa no caso brasileiro) sobre os fundamentos e objetivos do Estado Constitucional sobre o conteúdo dos direitos fundamentais (com destaque para os direitos socioambientais) e mesmo no que diz com o papel da Jurisdição Constitucional. (SARLET, 2013, p. 305).

10 (...) Trecho extraído da decisão publicada em BVrfGE (Coletânea oficial das decisões do Tribunal Constitucional Federal). (SARLET, 2013, p. 311).

${ }^{11}$ Com variações mais ou menos visíveis, como nos episódios do reconhecimento de cada dimensão de direitos fundamentais, o direito ao mínimo para a existência humana evoluiu até que se reconhecesse que este mínimo deve deferência e está associado à dignidade da pessoa humana. (LEAL; BOLESINA, 2013, p. 545).
} 
Contudo, o que se verifica é que "não se trata mais do que e quais são os direitos fundamentais que compõe o mínimo existencial, mas de que maneira os efetivar"12! Isso nos leva a refletir sobre a composição do mínimo existencial pelo direito de acesso à justiça, já que por este direito é que poderá o cidadão pleitear a proteção do Estado, na sua função jurisdicional, para fazer valer demais direitos básicos ali compreendidos como o direito à saúde, a benefícios da previdência social, à educação, dentre outros que compreendem um mínimo necessário para assegurar às pessoas uma existência digna em meio ao grupo que vivem, visando erradicar a pobreza e marginalidade.

Neste seguimento, visualiza-se que o direito de acesso à justiça, quando efetivamente garantido, assegurado aos jurisdicionados, é fator relevante para a promoção e proteção da dignidade da pessoa humana, cabendo ao Estado a implementação ampla de medidas tendentes à sua promoção sendo uma destas a entrega da prestação jurisdicional em tempo razoável. ${ }^{13}$

Por este entendimento, se tem presenciado a inserção do direito à razoável duração do processo nas "constituições dos Estados" ${ }^{\text {", }}$, elevando e reconhecendo seu status como de direito fundamental, que, inclusive, foi reconhecido em declarações de direitos como no caso da "Carta de Direitos Fundamentais da União Europeia, em seu art. $47^{\prime 15}$ e ainda na Carta da Corte Africana de Direitos Humanos que prevê em sua Declaração o direito do indivíduo de ser "julgado em um prazo razoável por um tribunal imparcial” ${ }^{16}$.

Também a Convenção Americana sobre Direitos Humanos, de 22 de novembro de 1969, conhecida como Pacto de San José de Costa Rica ${ }^{17}$, resguardou expressamente o direito de razoável

\footnotetext{
${ }^{12}$ Tornou-se lugar comum observar que a atuação positiva do Estado é necessária para assegurar o gozo de todos esses direitos sociais básicos. Não é surpreendente, portanto, que o direito ao acesso efetivo à justiça tenha ganho particular atenção na medida em que as reformas do welfare state tem procurado armar os indivíduos de novos direitos substantivos em sua qualidade de consumidores, locatários, empregados e, mesmo, cidadãos. De fato, o direito ao acesso efetivo tem sido progressivamente reconhecido como sendo de importância capital entre os novos direitos individuais e sociais, uma vez que a titularidade de direitos é destituída de sentido, na ausência de mecanismos para sua efetiva reivindicação. (CAPELLETTI; GARTH, 1988, p. 11).

${ }^{13}$ (...) o princípio da proteção judiciária se constitui um direito humano fundamental de acesso a uma ordem jurídica justa. E o acesso à justiça é o garantidor de todos os demais direitos, pois ao seu redor convergem todos os princípios e as garantias constitucionais, razão pela qual é uma maneira de assegurar a efetividade aos direitos de cidadania. Dessa forma, é um direito de suma importância, por ser um direito elementar do cidadão, pelo qual ocorre a materialização da cidadania e a efetivação da dignidade da pessoa humana. (SCHIEFELBEIN DA SILVA e SPENGLER, 2015, p.134)

${ }^{14}$ Pode ser citado como exemplo a Constituição Italiana que, entre outras garantias, assegura a "razoável duração do processo" em seu art. 111. Da mesma forma a Constituição da República Portuguesa prevê em seu art. 20.4 que "Todos têm direito a que uma causa em que intervenham seja objecto de decisão em prazo razoável e mediante processo equitativo".

${ }^{15}$ Toda a pessoa tem direito a que a sua causa seja julgada de forma equitativa, publicamente e num prazo razoável, por um tribunal independente e imparcial, previamente estabelecido por lei. Toda a pessoa tem a possibilidade de se fazer aconselhar, defender e representar em juízo.

${ }^{16}$ Artigo 70. 1.Toda pessoa tem o direito a que sua causa seja apreciada. Esse direito compreende: (...) d) o direito de ser julgado em um prazo razoável por um tribunal imparcial.

${ }^{17}$ I- Toda pessoa tem direito a ser ouvida, com as devidas garantias e dentro de um prazo razoável, por um juiz ou Tribunal competente, independente e imparcial, estabelecido anteriormente por lei, na apuração de qualquer acusação penal formulada contra ela, ou para que se determinem seus direitos ou obrigações de natureza civil, trabalhista, fiscal ou de qualquer outra natureza.
} 
duração do processo, o que, implicitamente, atribuiu à legislação brasileira a observância de tal preceito tendo em vista o Brasil ser signatário do Pacto de São José da Costa Rica e, conforme o "§ $2^{\circ}$ do art. $5^{\circ}$ da Constituição da República de $1988^{\prime 18}$, adotar os tratados internacionais em que seja parte.

Visando buscar eficiência na entrega da prestação jurisdicional e ainda tendo em vista medidas que vem sendo adotadas para ampliar e garantir o acesso dos cidadãos à justiça buscou o legislador pátrio assegurar que a tutela jurisdicional seja entregue em tempo razoável ${ }^{19}$.

Tal previsão constitucional foi positivada com a Emenda Constitucional no 45 de 2004 que tratou da reforma do judiciário, que além desta previsão tratou de outras medidas visando uma maior celeridade processual, gerando efetiva "alterações no sistema recursal cível brasileiro" ${ }^{20}$, onde se vislumbra o objetivo de se estabelecer maior previsibilidade na prestação jurisdicional por meio da nova ordem jurídica que vem sendo implantada no sistema jurídico brasileiro, tendo como justificativa o princípio da eficiência da administração da justiça.

Pretendeu o legislador assegurar de forma específica não só o acesso formal à justiça, garantido este com a previsão constitucional do art.5, XXXV, mas, também, o acesso substancial na medida em que deve ser proporcionado meios justos e adequados para a entrega da prestação jurisdicional visando, dentre outros obstáculos que devem ser superados para se assegurar esse efetivo acesso, que o processo deve ter um tempo razoável de duração ${ }^{21}$.

Mas o que seria uma razoável duração do processo?

O sistema jurídico pátrio não estabelece o que venha ser esse "tempo razoável", ficando este conceito submetido à interpretação do legislador e também do julgador.

Contudo, a doutrina vem se esforçando para esclarecer esse dispositivo, ou, pelo menos, estabelecer meios objetivos de seu alcance, chegando a afirmar que "a duração razoável do processo, assim, será aquela em que melhor se puder encontrar o meio-termo entre definição segura da existência do direito e realização rápida do direito cuja existência foi reconhecida pelo juiz". (WAMBIER, L; WAMBIER, T; MEDINA, 2005, p. 29).

Não há que se confundir o direito à razoável duração do processo com o direito a um processo célere, pois "(...) podemos ter uma justiça mais rápida, mas não necessariamente uma justiça mais cidadã". (SANTOS, 2008, p. 27). Um não é sinônimo do outro posto que de duração razoável do processo deve-se entender um processo com trâmite temporal apto a realizar com

\footnotetext{
${ }^{18}$ Os direitos e garantias expressos nesta Constituição não excluem outros decorrentes do regime e dos princípios por ela adotados, ou dos tratados internacionais em que a República Federativa do Brasil seja parte. ${ }^{19}$ (...) esse novo enfoque de acesso à justiça traz a ideia de que o princípio da proteção judiciária se constitui um direito humano fundamental de acesso a uma ordem jurídica justa. E o acesso à justiça é o garantidor de todos os demais direitos, pois ao seu redor convergem todos os princípios e as garantias constitucionais, razão pela qual é uma maneira de assegurar a efetividade aos direitos de cidadania. Dessa forma, é um direito de suma importância, por ser um direito elementar do cidadão, pelo qual ocorre a materialização da cidadania e a efetivação da dignidade da pessoa humana. (SCHIEFELBEIN DA SILVA e SPENGLER, 2015, p.134)

${ }^{20}$ Isso quer dizer que para a previsibilidade não resta alternativa a não ser a unidade do direito, derivada do exercício da função das Cortes Supremas. MARINONI, 2014. P. 109).

${ }^{21}$ Os obstáculos referentes ao acesso à justiça estão situados nos mais variados setores: econômico, social, político, cultural e burocrático, como especificados anteriormente. Esses fatores, por sua vez, trazem reflexos para a noção de desenvolvimento tanto econômico quanto desenvolvimento como liberdade. (MAILLART e SANCHES, 2012, p. 591).
}

Revista do Direito [ISSN 1982-9957]. Santa Cruz do Sul, v. 1, n. 51, p. 108-124, jan./abr. 2017. https://online.unisc.br/seer/index.php/direito/index 
eficiência a aplicação do direito material sem, contudo, ignorar ou violar o direito a um devido processo legal que garante às partes o contraditório, a ampla defesa, a produção de provas, duplo grau de jurisdição ${ }^{22}$.

Neste seguimento, é necessário se evidenciar que ao se buscar a tutela jurisdicional deve o Estado corresponder por meio de ações eficazes a promover o acesso à justiça de forma concreta e substancial a entregar a prestação em tempo razoável, ou seja, que garanta a efetividade da prestação almejada. ${ }^{23}$

O tempo do processo deve ser observado, pois "o direito deve seguir seu tempo normal, sem uma aceleração exacerbada e desmotivada que prejudicaria e muito a natural preservação de um direito em sua essência máxima". (OST, 1999, p.39)

A morosidade processual não pode ser um obstáculo ao acesso à justiça nem um convite à litigiosidade ${ }^{24}$, como também a celeridade processual exacerbada não pode ser um fator com objetivos de desafogar o judiciário apenas, gerando, assim, insegurança jurídica.

Portanto, fica evidenciado que a duração razoável do processo é fator de efetividade de acesso à justiça, na medida que conduz à segurança de se poder buscar a tutela jurisdicional plena e efetiva, a ser entregue de forma justa, com observância e respeito ao princípio do devido processo legal e ainda de forma rápida, dentro de prazo razoável a amadurecer o provimento almejado.

\section{A EFICÁCIA DOS DIREITOS FUNDAMENTAIS E A EFETIVAÇÃO DO DIREITO FUNDAMENTAL DE RAZOÁVEL DURAÇÃO DO PROCESSO.}

Quando o legislador positivou o direito à razoável duração do processo, reconhecendo-o como direito fundamental, deixou evidente que o jurisdicionado possui um direito subjetivo em face do Estado e em face dos demais cidadãos, em especial àquele com o qual possui uma relação processual.

Neste seguimento, cabe ao Estado a implementação de ações que visem proteger e também promover esse direito fundamental, almejando garantir ao cidadão um processo justo, com tramitação em tempo razoável, com a observância do devido processo legal e que the proporcione ampla defesa, contraditório, livre independência do juiz, duplo grau de jurisdição.

\footnotetext{
${ }^{22}$ Deve-se tomar o devido cuidado para que as coisas não se acelerem por demais, visto que o direito deve seguir seu tempo normal, sem uma aceleração exacerbada e desmotivada que prejudicaria e muito a natural preservação de um direito em sua essência máxima. (OST, 1999, p.39).

${ }^{23} \mathrm{O}$ direito de acesso aos tribunais reconduz-se fundamentalmente ao direito a uma solução jurídica de actos e relações jurídicas controvertidas, a que se deve chegar um prazo razoável e com garantias de imparcialidade e independência, possibilitando-se, designadamente, um correcto funcionamento das regras de contraditório, em termos de cada uma das partes poder deduzir as suas razões (de facto e de direito), oferecer as suas provas, controlar as provas do adversário e discretear sobre o valor e resultado de causas e outras.

(CANOTILHO, 2002, p. 433)

${ }^{24}$ COUTO apud Rodolfo de Camargo Mancuso menciona que isso "favorece a percepção, pelo jurisdicionado (efetivo ou virtual), de que a judicialização dos conflitos é o caminho natural ou o mesmo necessário para todos os interesses contrariados ou insatisfeitos; passa a (falsa) ideia de que toda e qualquer pretensão resistida ou insatisfeita deve ser resolvida por uma decisão de mérito, a ser oportunamente estabilizada pela coisa julgada; desestimula a busca pela solução alternativa dos conflitos, alvitre até hoje percebido com certa relutância pela população, acostumada à liturgia e à majestade da tradicional Justiça togada. (COUTO, 2012, P.371).
} 
Se trata dos "direitos de defesa" 25 , ou seja, direitos a ações negativas e também "direitos a prestações" ${ }^{26}$, que refletem a uma ação positiva, ambos por parte do Estado na realização dos direitos fundamentais.

Essa realização dos direitos fundamentais não deve ficar apenas na relação jurídica entre o Estado e o cidadão, mas, sobretudo, também na relação entre os próprios cidadãos, ou seja, a observância de proteção e também promoção dos direitos fundamentas deve se dar amplamente, de forma a ser observada por todos ${ }^{27}$.

Portanto, cabe ao Estado a promoção e proteção do direito fundamental de razoável duração do processo, proporcionando meios eficaciais fáticos e normativos para sua efetividade, posto que, como já visto, a efetividade desse direito fundamental resulta na garantia de realização de outro direito humano, o acesso à justiça, promovendo, assim, a dignidade da pessoa humana, já que o acesso à justiça, em especial nos dias atuais, é elemento do "mínimo existencial do ser humano"28.

Quando se fala na teoria vertical dos direitos fundamentais e, neste caso, em relação ao direito fundamental de duração razoável do processo, busca-se verificar a aplicabilidade dessa teoria na relação do cidadão com o Estado no âmbito do processo, ou seja, a aplicação dos direitos fundamentais na relação jurídica entre o cidadão e o Estado onde este tem o dever de sua observância $^{29}$.

Observando a Constituição Federal de 1988, em seu art. 5º $\S 1^{\circ}$, tem-se de forma expressa a imediata eficácia dos direitos fundamentais, o que não deixa dúvidas da sua aplicabilidade da relação jurídica Estado/cidadão.

\footnotetext{
${ }^{25}$ No âmbito dos direitos em face do Estado, que serão analisados em seguida, os direitos a ações negativas correspondem àquilo que comumente é chamado de 'direitos de defesa'. Já os direitos em face do Estado a uma ação positiva coincidem apenas parcialmente com aquilo que é chamado de 'direitos a prestações', (...).

Os direitos dos cidadãos contra o Estado, a ações estatais negativas (direitos de defesa) podem ser divididos em três grupos. O primeiro grupo é composto por direitos a que o Estado não impeça ou não dificulte determinadas ações do titular do direito; o segundo grupo, de direitos a que o Estado não afete determinadas características ou situações do titular do direito; o terceiro grupo, de direitos a que o Estado não elimine determinadas posições jurídicas do titular do direito. (ALEXY, 2015, p. 196).

${ }^{26}$ Os direitos que os cidadãos tem, contra o Estado, a ações estatais positivas podem ser divididos em dois grupos: aquele cujo objeto é uma ação fática e aquele cujo objeto é uma ação normativa. (...) Direitos a ações positivas normativas são direitos a atos estatais de criação de normas. (...) Quando se fala em direitos a prestações faz-se referência, em geral, a ações positivas fáticas. Tais direitos, que dizem respeito a prestações fáticas, que em sua essência, poderiam ser também realizadas por particulares, devem ser designados como direitos a prestações em sentido estrito. (ALEXY, 2015, p. 201-292).

${ }^{27}$ Essa ampliação da proteção jurídico-fundamental não foi uma exceção isolada, que era contrária à essência dos direitos fundamentais em si. Ela foi, ao contrário, sintomática para a mudança de significado, que se inicia, dos direitos fundamentais, que se esclarece disto, que o perigo da esfera jurídica do cidadão particular por outros poderes que estatais, simultaneamente, condiciona uma adaptação das funções dos direitos fundamentais a uma situação histórica mudada. (NIPPERDEY, 2012, p.61).

${ }^{28}$ A dignidade da pessoa humana e o assim chamado mínimo existencial são atualmente noções tidas como indissociáveis, cuidando-se, ademais, de figuras praticamente onipresentes no atual debate (pelo menos é o que se observa no caso brasileiro) sobre os fundamentos e objetivos do Estado Constitucional sobre o conteúdo dos direitos fundamentais (com destaque para os direitos socioambientais) e mesmo no que diz com o papel da Jurisdição Constitucional. (SARLET, 2013, p. 305).

${ }^{29} \mathrm{Na}$ direção do estado os direitos fundamentais valem ilimitadamente, porque aqui está defronte do titular de direitos fundamentais exclusivamente o estado vinculado aos direitos fundamentais. (NIPPERDEY, 2012, p. 63).
} 
Isso porque, a vinculação do Estado aos direitos fundamentais na sua relação jurídica com o cidadão decorre do reconhecimento dos direitos fundamentais da pessoa como direito subjetivo de defesa perante o Estado, impondo-Ihe limites em sua atuação. ${ }^{30}$

Contudo, o mesmo já não pode ser dito com relação aos direitos fundamentais a partir da concepção de sua eficácia imediata horizontal, inclusive.

Isto se dá ante a grande discussão ainda existente sobre a possibilidade de aplicação ampla e imediata dos direitos fundamentais, não só nas relações jurídicas que envolvam Estado e Cidadão, mas também naquelas entre particulares. ${ }^{31}$

Verifica-se, portanto, que nas relações processuais, e aqui falando numa relação ampla envolvente tanto entre as partes como entre partes e o Estado, cabe a este último assegurar a eficácia do direito fundamental de duração razoável do processo como forma de assegurar com efetividade o direito de acesso à justiça.

O processo é o instrumento pelo qual busca-se a aplicação do direito material na relação entre as partes envolvidas em litígio, cabendo ao Estado conduzir este instrumento na busca da efetividade da justiça. Contudo, a partir do momento que o processo se estende por demais no tempo, a prestação almejada acaba que por ter sua eficácia limitada ou sendo quase que ineficaz, posto que "a prestação jurisdicional tardia é fator de insegurança, na medida em que contribui para a intranquilidade do que seja, efetivamente, o sentido do Direito para os cidadãos." (WAMBIER, L; WAMBIER, T; MEDINA, 2005, p.27).

É fato que há uma crise processual, também denominada de crise do Judiciário, que evidencia uma morosidade processual e, consequentemente, uma violação do direito fundamental de razoável duração do processo, que também "decorre do aumento das demandas judiciais, resultado da ampliação do acesso à justiça" ${ }^{32}$ implementado após a promulgação da Carta da república de 1988.

Neste seguimento, também é importante evidenciar que na mesma proporção que vinha crescendo a preocupação em relação à morosidade do processo, também se verifica, atualmente, uma outra preocupação em relação ao tempo razoável do processo, e agora não só pela sua morosidade, mas também em relação à sua celeridade desmedida.

\footnotetext{
${ }^{30} \mathrm{~A}$ omissão do Constituinte não significa, todavia, que os poderes públicos (assim como os particulares) não estejam vinculados pelos direitos fundamentais. Tal se justifica pelo fato de que, em nosso direito constitucional, o postulado da aplicabilidade imediata das normas de direitos fundamentais (art. 50, § 10, da CF) pode ser compreendido como um mandado de otimização de sua eficácia, pelo menos no sentido de impor aos poderes públicos a aplicação imediata dos direitos fundamentais, outorgando-lhes, nos termos desta aplicabilidade, a maior eficácia possível. (SARLET, 2007a, p.360)

${ }^{31}$ Enquanto a plena eficácia dos direitos de defesa, integrados principalmente pelos direitos de liberdade, igualdade, direitos-garantia, garantias institucionais, direitos políticos e posições jurídicas fundamentais em geral, que, preponderantemente, reclamam uma atitude de abstenção dos poderes estatais e dos particulares (como destinatários dos direitos), virtualmente não costuma ser questionada, o mesmo não se pode afirmar com relação aos direitos sociais, ao menos não quando considerados na sua dimensão prestacional. (SARLET, 2015, p. 283).

${ }^{32}$ A tão falada crise do processo e da jurisdição não nasceu no vazio, mas sim em um contexto histórico em que novos direitos foram surgindo em decorrência de fatores culturais, econômicos, políticos e sociais que, somados, produziram novas categorias de demandas para as quais as estruturas processuais não podiam dar resposta satisfatória. (SALDANHA, 2010, p.676).
} 
Para combater a morosidade, medidas foram tomadas tendo em vista a edição da Emenda Constitucional 19 de 1998, que editou o "princípio da eficiência da administração pública" e a Emenda Constitucional 45 de 2004, a qual tratou da reforma do Judiciário.

Isso evidencia que tanto a morosidade processual como a "celeridade" ${ }^{33}$ do processo são fatores que não se coadunam com o direito fundamental de razoável duração do processo e, portanto, não podem se tornar um fator de "obstáculo de acesso à justiça" ${ }^{34}$, em que pese não haver um conceito e parâmetros terminológicos para se identificar com precisão o que e como seria um tempo de razoável duração do processo.

Por este motivo, cabe ao Estado a implementação de ações que busquem promover esse direito fundamental, ou seja, proporcionar ao jurisdicionado que o processo judicial tenha um efetivo tempo razoável de duração o que, direta ou indiretamente, acabará por proporcionar o acesso à justiça em seu conceito substancial e não apenas formal.

Para isso, deve editar medidas, prestações fáticas e normativas, visando a persecução de objetivos necessários à realização da justiça, "uma vez que a titularidade de direitos é destituída de sentido, na ausência de mecanismos para sua efetiva reivindicação". (CAPELLETTI; GARTH, 1988, p. 11).

A demora processual pode decorrer tanto da omissão do Estado/juiz, em relação à sua função de condução do processo, bem como da ação das partes (quando atuam com propósitos alheios aos fins do processo). Tanto uma conduta como a outra são violadoras de uma razoabilidade temporal do processo.

Em que pese a previsão constitucional do art. $5^{\circ}, \S 1^{\circ}$ da Constituição Federal de 1988 explicitar a aplicabilidade imediata dos direitos fundamentais, não se pode negar que o termo "razoável duração do processo" é muito amplo, aberto, dando margens a subjetivismos, quando o correto seria uma norma com previsão objetiva sobre o cumprimento desse direito fundamental.

Não se pode perder de vista que a razoável duração do processo deve ser fator de acesso à justiça no seu caráter substancial, vinculado a "um sistema jurídico moderno e igualitário que pretenda garantir, e não apenas proclamar os direitos de todos". (CAPELLETTI, 1988, p. 5).

Por isso, deve ser reconhecido que medidas foram tomadas para a realização de prestações fáticas e normativas relativamente à duração do processo e, consequentemente do acesso à justiça, tendo em vista a criação de varas especializadas e de pequenas causas com a possibilidade de, em alguns casos, o jurisdicionado atuar sem o acompanhamento de advogados, assistência judiciária aos economicamente desfavorecidos, possibilidade de realização de divórcio e inventário, conforme requisitos legais, em cartórios extrajudiciais, entre outras.

\footnotetext{
${ }^{33}$ Com as reformas que incidem sobre a morosidade sistêmica podemos ter uma justiça mais rápida, mas não necessariamente uma justiça mais cidadã. (SANTOS, 2008, p. 27).

${ }^{34}$ COUTO apud Rodolfo de Camargo Mancuso menciona que isso "favorece a percepção, pelo jurisdicionado (efetivo ou virtual), de que a judicialização dos conflitos é o caminho natural ou o mesmo necessário para todos os interesses contrariados ou insatisfeitos; passa a (falsa) ideia de que toda e qualquer pretensão resistida ou insatisfeita deve ser resolvida por uma decisão de mérito, a ser oportunamente estabilizada pela coisa julgada; desestimula a busca pela solução alternativa dos conflitos, alvitre até hoje percebido com certa relutância pela população, acostumada à liturgia e à majestade da tradicional Justiça togada. (COUTO, 2012, P.371).
} 
Somado a isso, no que tange às recentes reformas recursais cíveis vivemos a implantação da Súmula Vinculante, repercussão geral, súmula impeditiva de recursos e incidente de recursos repetitivos e ainda a implantação de instituto precedentalista com o novo código de processo civil, o que demonstra estar o Estado na busca de medidas que acelerem a entrega da prestação jurisdicional.

Contudo, estas meditas tomadas mais demonstram a preocupação do Estado em desafogar o judiciário do que efetivamente proporcionar um tempo razoável na duração do processo o que, sem dúvidas, afeta o acesso à justiça.

Por isso se evidencia a necessidade de edição de norma específica regulamentando esse direito fundamental, tratando, especifica e objetivamente de quais condutas (omissivas e/ou comissivas) seriam consideradas violadoras de tal direito fundamental, até mesmo para que se possa falar de responsabilização do Estado por infração a esse dispositivo constitucional.

Neste seguimento, o que se tem hoje é a previsão constitucional de que "a todos, no âmbito judicial e administrativo, são assegurados a razoável duração do processo e os meios que garantam a celeridade de sua tramitação", estando tal previsão positivada no rol dos direitos e garantias fundamentais da Constituição de 1988.

Complementando essa disposição, o art. $5^{\circ}$ da $\mathrm{CF} / 88$, em seu parágrafo $1^{\circ}$, dispõe que "as normas definidoras dos direitos e garantias fundamentais têm aplicação imediata", o que demonstra a possibilidade de sua eficácia direta nas relações jurídicas envolvendo o Estado e o cidadão, proporcionado aos jurisdicionados "situações jurídicas imediatamente desfrutáveis, a serem efetivadas por prestações positivas ou negativas, exigíveis do Estado ou de outro eventual destinatário da norma". (BARROSO, 2002, p. 80).

A violação desse dispositivo constitucional pode ensejar a pretensão de reparação de danos morais e/ou materiais em face do Estado, o que não seria a solução mais adequada de proteção ao cidadão jurisdicionado, tendo em vista que seriam mais processos sobrecarregando o Judiciário pelo fato de não se estar combatendo a causa, mas sim apenas o efeito.

Com base nisso, enquanto não se editar norma específica tratando desse direito fundamental, hoje tão necessária para que a morosidade e a celeridade processual não afetem o acesso à justiça, cabe ao Estado/juiz, na condução do processo, utilizar dos meios legais amplos e interpretá-los de acordo com a Constituição para fazer valer esse direito fundamental e, assim, prezar por um processo com duração de tempo necessária para seu amadurecimento na entrega da prestação jurisdicional, com observância, em especial, do devido processo legal, proporcionando, assim, a segurança jurídica de respeito ao contraditório, ampla defesa, adequada fundamentação das decisões judiciais e duplo grau de jurisdição.

\section{CONSIDERAÇÕES FINAIS}

A questão problema a ser resolvida com a presente pesquisa foi verificar se é possível falar em aplicação da teoria da eficácia dos direitos fundamentais para a efetivação do direito fundamental de acesso à justiça a partir da concepção de razoável duração do processo? 
Para isso, observou-se que a teoria da eficácia dos direitos fundamentais contempla situações de aplicação imediata ou medita dos direitos fundamentais, para isso reconhecem que os direitos fundamentais se configuram em direitos subjetivos perante o Estado, na relação existente entre este e o Cidadão. Por outro lado, a questão maior é a configuração destes direitos fundamentais como subjetivos também na relação entre particulares, sendo o caso de se observar cada teoria em sua aplicação.

Neste seguimento, ainda no afã de resolver a questão mencionada, verificou-se que o direito fundamental de razoável duração do processo possui ampla relação com o direito humano de acesso à justiça, na medida em que o acesso à justiça se constitui em elemento integrante do mínimo existencial do ser humano.

Para que o cidadão possa fazer valer seus direitos quando violados, deve buscar o Judiciário para aplicação do direito material ao caso em concreto, o que demonstra estar o acesso à justiça vinculado à efetividade do direito material, como por exemplo, direito à saúde, à segurança, à integridade física e moral, enfim, à realização e efetivação daquilo que não the foi reconhecido por quem tinha a obrigação de realizar.

Contudo, quando o processo apresenta certa morosidade na entrega da prestação jurisdicional, corre-se o sério risco de que essa prestação não alcance a efetividade almejada, se tornando, em muitos casos, ineficiente.

Do mesmo modo, quando se tem um processo com celeridade exacerbada, seja por fugir de certa formalidade, seja até mesmo pelo engessamento do direito (através de sumulas vinculantes, impeditiva de recursos, sistema precedentalista, etc) também fica o cidadão sem a certeza de um processo justo, que tenha observado o devido processo legal e demais garantias constitucionais.

Ou seja, tanto a morosidade como a celeridade processual podem se tornar obstáculo de acesso à justiça.

Portanto surge a necessidade de se observar o direito de acesso à justiça a partir da teoria da eficácia dos direitos fundamentais, com enfoque na duração razoável do processo.

Pelo que foi observado, o Brasil vem adotando a teoria da eficácia imediata e direta dos direitos fundamentais, o que não se torna possível sua aplicação em relação ao direito fundamental da duração razoável do processo, o qual, por se tratar de norma aberta em seu conceito, exige a edição de lei infraconstitucional regulamentando-o, o que nos leva à conclusão de que a teoria mais condizente, neste caso, é a teoria mediata, indireta.

De qualquer forma, o que se verifica é que vem ocorrendo violação ao direito de acesso à justiça, na medida em que a morosidade que assola os processos em trâmite vem sendo substituída por medidas que podem levar a uma celeridade dos processos, sendo estes dois fatores determinantes para gerar obstáculo ao direito humano em questão, qual seja, de acesso à justiça.

Há uma necessidade urgente de que o legislador regulamente a efetiva "razoável duração do processo", tornando possível a eficácia desse direito fundamental, não deixando que o acesso à justiça continue sendo obstaculizado, já que tanto a morosidade como a celeridade podem gerar acesso à justiça apenas a grupos determinados e não de forma ampla geral, como deve ser. 


\section{REFERÊNCIAS}

ALEXY, Robert. Teoria dos Direitos Fundamentais. Tradução Virgílio Afonso da Silva. São Paulo: Malheiros Editores, 2015.

BARROSO, Luís Roberto. Temas de Direito Constitucional. 2. Ed. Rio de Janeiro: Rnovar, 2002.

CANOTILHO, J.J. Gomes. Direito Constitucional e Teoria da Constituição. 6a Ed. Coimbra: Almedina, 2002.

CAPPELLETTI, Mauro; BRYANT, Garth. Acesso à Justiça. Tradução e revisão: Ellen Gracie Northfleet: Porto Alegre, 1988.

COUTO, Mônica Bonetti. A Duração Razoável do Processo como Direito Fundamental no Brasil: Mecanismos e Alternativas à sua Implementação. Os desafios dos Direitos Humanos Fundamentais na América Latina e na Europa. Organizadores: BAEZ, Narciso Leandro Xavier; DA SILVA, Rogério Luiz Nery; SMORTO, Guido. Joaçaba: Editora Unoesc, 2012.

DE ANDRADE, José Carlos Vieira. Os direitos, liberdades e garantias no âmbito das relações entre particulares. Constituição, direitos fundamentais e Direito Privado. Porto Alegre: Livraria do Advogado, 2003;

FABIAN, Christoph. O dever de informar no direito civil. São Paulo: Revista dos Tribunais, 2002, p. 71.

LEAL, Mônica Clarissa Hennig; BOLESINA, Iuri. Mínimo Existencial Versus Mínimo Vital: Uma análise dos limites e possibilidades de atuação do Poder Judiciário na sua garantia e no controle jurisdicional de políticas públicas. In: ALEXY, Robert; BAEZ, Narcizo Leandro Xavier; SANDKÜHLER, Hans Jörg; HAHN, Paulo (Orgs.). Níveis de Efetivação dos Direitos

Fundamentais Civis e Sociais: Um diálogo Brasil e Alemanha. Joaçaba: Unoesc, 2013.

MAILLART, Adriana Silva; SANCHES, Samyra Dal Farra Naspolini. O Direito Fundamental de Acesso à Justiça e Suas Implicações para o Direito Fundamental ao Desenvolvimento. Os desafios dos Direitos Humanos Fundamentais na América Latina e na Europa. Organizadores: BAEZ, Narciso Leandro Xavier; DA SILVA, Rogério Luiz Nery; SMORTO, Guido. Joaçaba: Editora Unoesc, 2012.

NIPPERDEY, Hans Carl. Direitos Fundamentais e Direito Privado. In GÜNTER, Dürig; NIPPERDEY, Hans Carl; SCHWABE, Jürgen. Direitos Fundamentais e Direito Privado. Organizador Luis Afonso Heck. Porto Alegre: Sergio Antonio Fabris Editor, 2012.

OST, François. O Tempo do Direito. Lisboa: Instituto Piaget, 1999.

SANTOS, Boaventura de Souza. Para uma revolução democrática da justiça. $2^{\mathrm{a}}$ ed., São Paulo: Cortez, 2008.

SARLET, Ingo Wolfgang. A eficácia dos direitos fundamentais, $8^{a}$ edição, revista, atualizada e ampliada. 8a . ed. Porto Alegre: Editora Livraria do Advogado, 2007;

SARLET, Ingo Wolfgang. Direitos Fundamentais e Direito Privado: algumas considerações em torno da vinculação dos particulares aos direitos fundamentais;

As Dimensões da Dignidade da pessoa Humana: Construindo uma compreensão jurídico-constitucional necessário e possível. In;MAURER, Béatrice; SARLET. Ingo Wolfgang; Seelman, Kurt; Kloepfer, Michael; Häberle, Peter. Dimensões da Dignidade. Ensaios de filosofia do direito e direito constitucional. Tradução Ingo Wolfgang Sarlet; Pedro Scherer de Mello Aleixo e Rita Dostal Zanini: Porto Alegre, Livraria do Advogado, 2005. 
SCHIEFELBEIN DA SILVA, Queli Cristiane; SPENGLER, Fabiana Marion. O ACESSO À JUSTIÇA COMO DIREITO HUMANO FUNDAMENTAL: A BUSCA DA EFETIVAÇÃO DA RAZOÁVEL DURAÇÃO DO PROCESSO POR MEIO DO PROCESSO ELETRÔNICOO / ACCESS TO JUSTICE AS A FUNDAMENTAL HUMAN RIGHT: THE SEARCH FOR THE EFFECTIVENESS OF THE REASONABLE DURATION OF THE. Espaço Jurídico: Journal of Law [EJJL], [S.I.], v. 16, n. 1, p. 131-148, nov. 2014. ISSN 2179-7943. Disponível em:

<http://editora.unoesc.edu.br/index.php/espacojuridico/article/view/2555/3776>. Acesso em: 10 Mai. 2015.

SOMBRA, Thiago Luís Santos. A Eficácia dos direitos fundamentais nas relações jurídicoprivada. Porto Alegre: Sergio Antonio Fabris Editor, 2004, p. 124.

STEINMETZ, Wilson Antônio. A vinculação dos particulares a direitos fundamentais. São Paulo. Editora Malheiros Ltda, 2004;

VIEIRA DE ANDRADE, José Carlos. Os direitos, liberdades e garantias no âmbito das relações entre particulares;

WAMBIER, Luiz Rodrigues; WAMBIER, Teresa Arruda Alvim; MEDINA, José Miguel Garcia. Breves Comentários à nova sistemática processual civil. E. Ed. Rev. Atual. e ampli. São Paulo: Editora Revista dos Tribunais, 2005.

\section{COMO CITAR ESSE DOCUMENTO:}

RESCHKE, Ana Paula Goldani Martinotto; BAES, Narciso Leandro Xavier. A eficácia do direito fundamental de acesso à justiça pela efetividade do direito de razoável duração do processo. Revista do Direito, Santa Cruz do Sul, v. 1, n. 51, jul. 2017. ISSN 1982-9957. Disponível em: $<$ https://online.unisc.br/seer/index.php/direito/article/view/8639>. Acesso em: doi:http://dx.doi.org/10.17058/rdunisc.v1i51.8639. 